\title{
Rapid Interference-free Analysis of $\beta$-Lapachone in Clinical Samples Using Liquid Chromatography-Mass Spectrometry for a Pharmacokinetic Study in Humans
}

\author{
Bo Kyung KIM, ${ }^{*}, * *$ Mi-Ri Gwon, $* * *$ Woo Youl Kang,* In-Kyu LeE, ${ }^{* * *}$ Hae Won LeE,* \\ Sook Jin SeOng, $* * *$ Seungil Cho, ${ }^{* * \dagger}$ and Young-Ran YoON $* * *+$ \\ *Department of Molecular Medicine, School of Medicine, Kyungpook National University and Department of \\ Clinical Pharmacology, Kyungpook National University Hospital, Daegu, 41944, Republic of Korea \\ **Clinical Omics Institute, School of Medicine, Kyungpook National University, Daegu, 41944, Republic of Korea \\ ***Department of Internal Medicine, Kyungpook National University, Kyungpook National University Hospital, \\ Daegu, 41944, Republic of Korea
}

\begin{abstract}
A rapid analytical method developed for the analysis of $\beta$-lapachone in in vitro samples could not be directly applied to the analysis of clinical samples because of interference from unknown substances. Here, we developed and validated a rapid interference-free analytical method to accurately determine $\beta$-lapachone levels in human plasma using liquid chromatography-tandem mass spectrometry. First, we achieved the baseline-separation of $\beta$-lapachone from any interfering substances within a total run time of $4 \mathrm{~min}$ by adjusting the eluent strength of the mobile phase. Second, precursor-ion scanning revealed the identity of the interfering substances. Sulfonate- or glucuronide-conjugated metabolites were converted to $\beta$-lapachone in an electrospray ion source, causing interference. In a method validation study, calibration curves for $\beta$-lapachone in human plasma were linear over a concentration range from 0.5 to $200 \mathrm{ng} / \mathrm{mL}$ $(r>0.999)$, and the lower limit of quantification was $0.5 \mathrm{ng} / \mathrm{mL}$. The other validation parameters, including intra- and interday accuracy and precision, were acceptable with a coefficient of variation less than $10 \%(n=5)$. The validated analytical method was successfully applied to a pharmacokinetic study of a single, oral dose of $100 \mathrm{mg}$ MB12066 (a clinical form of $\beta$-lapachone) in healthy volunteers.
\end{abstract}

Keywords Interference, $\beta$-lapachone, LC-MS/MS, MB12066, pharmacokinetic study

(Received October 22, 2020; Accepted December 21, 2020; Advance Publication Released Online by J-STAGE December 25, 2020)

\section{Introduction}

$\beta$-Lapachone (3,4-dihydro-2,2-dimethyl-2H-naphthol[1,2-b]pyran5,6-dione) is a poorly water-soluble, light-sensitive orthonaphthoquinone that can be obtained from the bark of South American Lapacho trees (Tabebuia avellanedae). ${ }^{1}$ It is known to have numerous beneficial properties, including anticancer, ${ }^{2-4}$ anti-inflammatory, ${ }^{5}$ antifungal, ${ }^{6}$ and anti-oxidant effects. ${ }^{7,8}$ As a result, clinical trials have recently been performed to evaluate its safety and efficacy in humans. ${ }^{9,10}$ For researchers to handle numerous clinical samples $(>1000)$ obtained at multiple different time points from a large number of subjects, it is critical to develop and thoroughly validate an analytical method with high speed, sensitivity, and reliability.

Liquid chromatography-mass spectrometry (LC-MS)-based analytical methods have been developed to analyze $\beta$-lapachone in various sample matrices, including blood, plasma, tissues, and cell extracts. ${ }^{11-15}$ For example, Savage et al. used an HPLCMS to determine $\beta$-lapachone levels in mouse plasma and tumor tissues at multiple time points after the intraperitoneal

† To whom correspondence should be addressed.

E-mail: chosi1@gmail.com (S. C.); yry@knu.ac.kr (Y.-R. Y.) administration of $60 \mathrm{mg} / \mathrm{kg}$ ARQ 501 (a clinical form of $\beta$-lapachone). ${ }^{12}$ In their study, the lower limit of quantification (LLOQ) for $\beta$-lapachone was $3.0 \mathrm{ng} / \mathrm{mL}$, the total run time was $3.75 \mathrm{~min}$, and no interference in blank plasma samples was observed. Miao et al. also studied the in vitro metabolism of ARQ 501 in whole blood and in mammalian hepatocytes and cultured human cells using ultrahigh-performance liquid chromatography-MS. ${ }^{13,14}$ They focused on the qualitative analysis of $\beta$-lapachone metabolites, including glucuronide and sulfonate conjugates. ${ }^{14}$ Kim et al. used HPLC and LC-MS to analyze $\beta$-lapachone and its degradation products produced under the stress of heat, light, or acid/base conditions. ${ }^{16}$ The LLOQ for $\beta$-lapachone was $0.235 \mu \mathrm{g} / \mathrm{mL}$, and the run time was 5 min. Recently, Putnma et al. developed a rapid, sensitive and robust LC-MS method to quantify $\beta$-lapachone in human plasma after the administration of ARQ-761, a pro-drug of $\beta$-lapachone. However, they did not characterize the interference observed in clinical samples. ${ }^{17}$

In the present study, we aimed to develop an LC-MS-based analytical method with high sensitivity and reliability that enables the rapid, accurate determination of $\beta$-lapachone levels in human plasma. The samples were obtained at 12 time points from eight healthy volunteers who received a single dose of $100 \mathrm{mg}$ MB12066 (a clinical form of $\beta$-lapachone). The HPLC 
conditions were optimized to achieve sufficient selectivity for $\beta$-lapachone analysis within a short period. In the meantime we identified the cause of interference arising from the clinical samples, which hampered their rapid analysis. The developed analytical method was validated according to the guidelines issued by both the United States Food and Drug Administration (US FDA) and the Korean Ministry of Food and Drug Safety (MFDS) and was then applied to a pharmacokinetic study of $\beta$-lapachone in humans. ${ }^{18,19}$

\section{Experimental}

\section{Materials and reagents}

MB12066, $\beta$-lapachone, and $\beta$-lapachone- $d_{6}$ (internal standard, IS) were supplied by KT\&G Life Sciences Co., Ltd. (Suwon, Republic of Korea). HPLC-grade acetonitrile and ammonium acetate were obtained from Merck (Darmstadt, Germany). Formic acid was purchased from Sigma-Aldrich (St. Louis, MO, USA). Heparinized blank human plasma was acquired from BioChemed Services (Winchester, VA, USA). Deionized distilled water ( $18 \mathrm{M} \Omega \cdot \mathrm{cm}$ resistivity) was freshly prepared as needed using a Milli-Q purification system (Millipore; Billerica, MA, USA).

\section{LC-MS/MS conditions}

An Agilent 1200 Series HPLC system (Agilent, Santa Clara, CA, USA) equipped with an automatic degasser, a binary pump, and a thermostated autosampler was used for the analysis. Chromatographic separation was performed on a Zorbax Eclipse $\mathrm{XDB}_{-\mathrm{C}_{18}}$ column $(2.1 \times 150 \mathrm{~mm}, 3.5 \mu \mathrm{m}$, Agilent $)$ at $40^{\circ} \mathrm{C}$. Mobile phase solvent A was $5 \mathrm{mM}$ ammonium acetate in water with $0.1 \%$ formic acid $(\mathrm{v} / \mathrm{v})$, and mobile phase solvent B was $100 \%$ acetonitrile. The mobile phase was filtered through a $0.22-\mu \mathrm{m}$ membrane filter (Millipore, Dublin, Ireland) prior to use. Unless otherwise specified, it was used in a mixing ratio of $3: 7$ (solvent A:solvent B, v/v) and flowed at a rate of $0.2 \mathrm{~mL} / \mathrm{min}$. The total run time for each analysis was $4.0 \mathrm{~min}$, unless otherwise specified. The autosampler, maintained at $10^{\circ} \mathrm{C}$, injected $3 \mu \mathrm{L}$ of each sample into the system.

A triple-quadrupole mass spectrometer (API5000, SCIEX, Framingham, MA, USA) coupled with an electrospray ionization (ESI) source was used to analyze the eluates from the HPLC system. Multiple reaction-monitoring mode (MRM) was used for a highly sensitive quantitative analysis of $\beta$-lapachone in positive ion mode. A precursor ion scan was performed in both positive and negative ion modes to identify interfering substances. The optimized MS parameters were as follows: source temperature, $600^{\circ} \mathrm{C}$; ion spray voltage, $5.5 \mathrm{kV}$; declustering potential, 46 and $121 \mathrm{~V}$ for $\beta$-lapachone and IS respectively; entrance potential, $8 \mathrm{~V}$; collision energy, 27 and $25 \mathrm{eV}$ for $\beta$-lapachone and IS, respectively; collision cell exit potential, $16 \mathrm{eV}$ for $\beta$-lapachone and IS; curtain gas flow, $10 \mathrm{~L} /$ min of nitrogen gas; ion source gas $1,11 \mathrm{~L} / \mathrm{min}$ of zero air; ion source gas 2, $11 \mathrm{~L} / \mathrm{min}$ of zero air. Analyst 1.5.2 software (SCIEX) was used for instrument control and data acquisition and processing.

\section{Preparation of standards and quality controls}

Stock solutions of $\beta$-lapachone and IS were prepared in $100 \%$ acetonitrile at a concentration of $1 \mathrm{mg} / \mathrm{mL}$ and stored at $-20^{\circ} \mathrm{C}$. All $\beta$-lapachone and IS solutions were stored in light-resistant containers, and light exposure was minimized throughout the sample preparation and analysis procedures. The entire sample preparation process was also carried out with the samples on ice to avoid thermal degradation. Working standard solutions of $\beta$-lapachone at concentrations of 10,20,100,200,1000, and $4000 \mathrm{ng} / \mathrm{mL}$ and an IS solution of $50 \mathrm{ng} / \mathrm{mL}$ were prepared through serial dilution of the stock solution with $50 \%$ acetonitrile. All standard solutions were also stored at $-20^{\circ} \mathrm{C}$ prior to use.

Blank plasma was spiked with the working standard solutions to prepare calibration standards at concentrations of $0.5,1,5$, $10,50,100$, and $200 \mathrm{ng} / \mathrm{mL}$ for $\beta$-lapachone and $5 \mathrm{ng} / \mathrm{mL}$ for IS. Quality control (QC) samples were prepared at four different concentration levels: 0.5 (LLOQ), 1.5 (low quality control, LQC), 16 (middle quality control, MQC), and $160 \mathrm{ng} / \mathrm{mL}$ (high quality control, HQC) for $\beta$-lapachone. Plasma standards for calibration and QC samples were prepared daily prior to analysis.

\section{Plasma sample preparation}

All plasma samples were stored at $-70^{\circ} \mathrm{C}$ and allowed to thaw gradually on ice before processing. An aliquot $(100 \mu \mathrm{L})$ of a plasma sample was then transferred to an amber microcentrifuge tube. The IS working standard solution $(20 \mu \mathrm{L})$ was added to the tube. After brief vortex-mixing, acetonitrile $(180 \mu \mathrm{L})$ was added for protein precipitation. The resulting solution was vortexed for $5 \mathrm{~min}$ and centrifuged at $16100 \mathrm{~g}$ for $10 \mathrm{~min}$ at $4^{\circ} \mathrm{C}$. The supernatant was transferred to an HPLC vial for further LCMS/MS analysis.

\section{Method validation}

Using guidelines developed by the US FDA and the Korean MFDS, the method was validated for specificity, sensitivity, linearity, accuracy, precision, percent recovery, and stability, as described in other studies.20-22 Briefly, specificity was determined through analysis of drug-free plasma samples from six different individuals. Interference from endogenous substances at the LC retention times of $\beta$-lapachone and IS was investigated using blank plasma spiked with $\beta$-lapachone (LLOQ) and IS ( $5 \mathrm{ng} / \mathrm{mL})$. The sensitivity was represented by the LLOQ, the signal of which was 10 times the signal-to-noise ratio $(S / N)$. Linearity was determined by fitting a calibration curve plotted as the ratio of $\beta$-lapachone and IS peak areas versus the nominal $\beta$-lapachone concentration, using a weighted $(1 / x)$ least-squares regression. Intraday accuracy and precision were evaluated from the results of five replicate analyses of each QC sample (LLOQ, LQC, MQC, and HQC) on the same day, whereas interday accuracy and precision were evaluated on the basis of the results of analyses from five different days. Accuracy was expressed as the percent deviation: (measured concentration/nominal concentration) $\times 100$. Precision was calculated as the relative standard deviation (RSD). For the stability test, the peak area ratios were compared between the newly prepared samples and those stored under four different conditions: (i) post-preparation stability, $25 \mathrm{~h}$ at $10^{\circ} \mathrm{C}$; (ii) freeze-thaw stability for three cycles; (iii) short-term stability for $6 \mathrm{~h}$ at $4^{\circ} \mathrm{C}$; and (iv) long-term stability for 235 days at $-70^{\circ} \mathrm{C}$. The stability of stock solutions was also analyzed for 37 days at $-20^{\circ} \mathrm{C}$. Stability was measured in triplicate at low $(1.5 \mathrm{ng} / \mathrm{mL})$ and high $(160 \mathrm{ng} / \mathrm{mL})$ QC concentrations. Recovery was determined at three concentrations $(1.5,16$, and $160 \mathrm{ng} / \mathrm{mL}$ ) in triplicate.

\section{Pharmacokinetic application}

The validated method was used to determine time-dependent plasma levels of $\beta$-lapachone after the administration of a single $100 \mathrm{mg}$ dose of MB12066 to eight healthy Korean male volunteers. The pharmacokinetic study protocol was approved 
by the Institutional Review Board of Kyungpook National University Hospital (Daegu, Republic of Korea), and the trial was registered in a public trial registry at ClinicalTrials.gov (Identifier: NCT02338856). Written informed consent was obtained from all of the subjects. The details of this clinical study have been described elsewhere. ${ }^{10}$ Each blood sample $(5 \mathrm{~mL})$ was placed in a sodium heparinized vacutainer before $(0 \mathrm{~h})$ and at 1, 2, 3, 4, 5, 6, 7, 8, 9, 10, and $12 \mathrm{~h}$ after oral administration. During the study, all sample-handling procedures were carried out on ice, and plasma was immediately separated from blood cells by centrifugation at $1620 \mathrm{~g}$ for $10 \mathrm{~min}$ at $4^{\circ} \mathrm{C}$. The plasma was subsequently transferred to an amber microcentrifuge tube and stored at $-70^{\circ} \mathrm{C}$ prior to analysis. Pharmacokinetic parameters such as the area under the curve of plasma concentration from time 0 to the time of last quantifiable concentration $\left(\mathrm{AUC}_{\text {last }}\right)$, maximum plasma concentration $\left(C_{\max }\right)$, time to reach $C_{\max }\left(T_{\max }\right)$, and the half-life $\left(t_{1 / 2}\right)$ were calculated using the Phoenix WinNonlin 6.4 software (Certara, NJ, USA).

\section{Results and Discussion}

LC-MS/MS: Method development for the analysis of $\beta$-lapachone

The LC conditions were first optimized to develop an analytical method with a total run time of $3 \mathrm{~min}$ for sufficient throughput. To achieve sub-ng/mL sensitivity, we selected the transition $\mathrm{m} / \mathrm{z} \quad 243 \rightarrow 187$ on the basis of the product ion spectrum of $[\mathrm{M}+\mathrm{H}]^{+}$(Fig. 1a). Blank plasma samples spiked with $\beta$-lapachone standard showed good sensitivity and specificity without any noticeable interference when they were analyzed using a mobile phase of $80 \%$ acetonitrile (data not shown). However, all clinical plasma samples obtained $3 \mathrm{~h}$ after the administration of MB12066 showed substantial interference under the same condition (Fig. 1b). To develop an analytical method with a total run time of $3 \mathrm{~h}$, we attempted to avoid the interference by using different transition channels such as $\mathrm{m} / \mathrm{z}$, $243 \rightarrow 159$ and $187 \rightarrow 159$; however, this approach was unsuccessful. Unexpectedly, the product ion spectra of $\mathrm{m} / \mathrm{z}, 243$ for interfering peaks $(1.64,2.03$, and $2.53 \mathrm{~min})$ showed the same fragmentation pattern of protonated $\beta$-lapachone as in Fig. 1a. Given the high purity of the $\beta$-lapachone standard (>99\%), the presence of structural isomers in the drug could be ruled out. Because all blood samples at $3 \mathrm{~h}$ were collected from healthy, fasting volunteers, we reasonably assumed that the interference did not arise from food.

To separate the interfering substances from $\beta$-lapachone, we adjusted the eluent strength of the mobile phase. Fortunately, their separation was achieved when the acetonitrile content in the mobile phase was lowered from 80 to $70 \%$ (Fig. 1c). The retention time of the $\beta$-lapachone increased from 2.61 to 3.18 min because of its hydrophobic nature. Notably, however, the retention time associated with the major interfering peak decreased from 2.53 to $1.88 \mathrm{~min}$, whereas those associated with the two other interfering peaks at 1.64 and $2.03 \mathrm{~min}$ did not noticeably change. These results indicate that the chemical structure associated with the major peak is very different from those associated with the other two peaks.

\section{LC-MS/MS: Identification of interfering substances}

To identify these interfering substances, we performed a precursor ion scan for $\mathrm{m} / \mathrm{z} 243$ in positive-ion mode; however, this scan did not provide a useful signal. Worse yet, a precursor ion scan for a deprotonated molecule, $\mathrm{m} / \mathrm{z} 241$, in negative-ion mode also failed to produce an adequate signal. Interestingly, however, a precursor ion scan for $\mathrm{m} / \mathrm{z}, 243$ in negative-ion mode
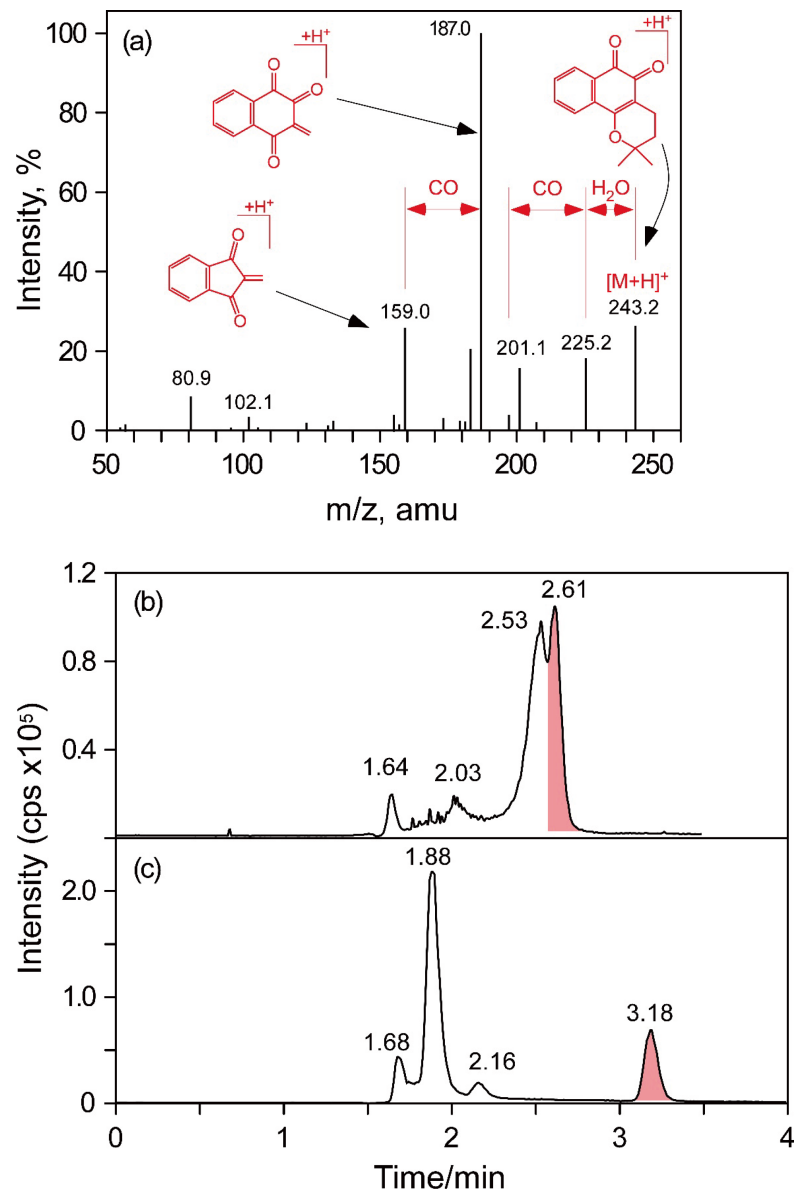

Fig. 1 LC-MS method development. (a) Product ion mass spectrum of the protonated molecular ion of $\beta$-lapachone and (b and $\mathrm{c}$ ) representative LC-MS chromatograms for the separation of $\beta$-lapachone in human plasma $3 \mathrm{~h}$ after oral administration of a single dose of $100 \mathrm{mg} \mathrm{MB12066}$. The mobile phase was composed of $5 \mathrm{mM}$ ammonium acetate in water with $0.1 \%$ formic acid (solvent $\mathrm{A}$ ) and $100 \%$ acetonitrile (solvent B) at a mixing ratio of (b) 2:8 and (c) 3:7. $\beta$-Lapachone was monitored in positive-ion mode using the transition $m / z, 243 \rightarrow 187$.

revealed their identity. Figure 2 shows the precursor ion spectra of $\mathrm{m} / \mathrm{z} 243$ for the chromatographic peaks at 1.88 and $2.16 \mathrm{~min}$, scanning from $\mathrm{m} / \mathrm{z}, 250$ to 600 . The former shows an abundant precursor ion at $m / z, 323$ (Fig. 2a), corresponding to [M+H+80]- . The $\mathrm{m} / \mathrm{z}$ difference of $80 \mathrm{amu}$ between the parent and daughter ions is known as the characteristic transition of a sulfonate conjugated metabolite. ${ }^{14}$ Meanwhile, another peak at $2.16 \mathrm{~min}$ showed an abundant precursor ion at $\mathrm{m} / \mathrm{z} 419$ (Fig. 2b), corresponding to $[\mathrm{M}+\mathrm{H}+176]^{-}$. This gain of $176 \mathrm{amu}$ can be attributed to the formation of a monoglucuronide conjugate. Our assignments are well supported by the MS/MS results obtained from in vitro metabolite studies. ${ }^{14}$ Thus, we confirmed that the major interfering substance was a sulfonate conjugate, whereas the other minor one was a monoglucuronide conjugate.

The chromatographic peak for $\mathrm{m} / \mathrm{z}, 243$ at $1.68 \mathrm{~min}$ yielded numerous precursor ions at $\mathrm{m} / \mathrm{z} 279,301,405,419,485$, and 595 (Fig. 2c). Both $m / z$ 419, [M+H+176 $]^{-}$, and $\mathrm{m} / \mathrm{z}$ 595, $[\mathrm{M}+\mathrm{H}+2 \times 176]^{-}$, could be produced from a diglucuronide conjugate (M4 in Ref. 14) or a bisglucuronide conjugate (M5 in Ref. 14). Because we could not observe $\mathrm{m} / \mathrm{z} 351$, which is an additional characteristic ion for the bisglucuronide conjugate, we assumed that $\mathrm{m} / \mathrm{z} 595$ and 419 originated from the 

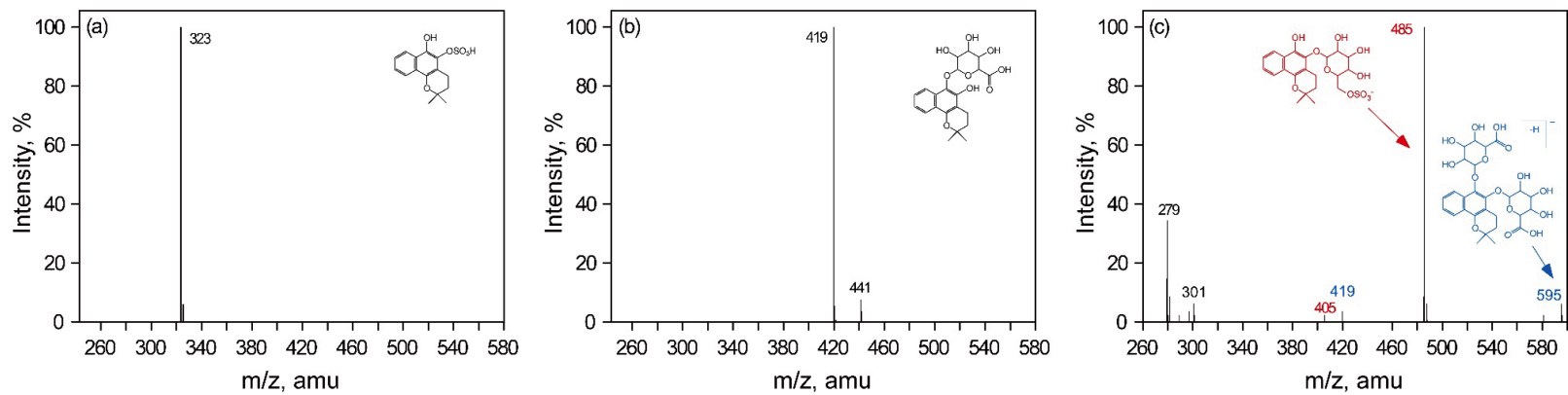

Fig. 2 Precursor ion spectra of $m / z, 243$ in negative-ion mode for the chromatographic peaks at (a) 1.88 , (b) 2.16 , and (c) $1.68 \mathrm{~min}$.

diglucuronide conjugate. Both $\mathrm{m} / \mathrm{z}, 485,[\mathrm{M}+\mathrm{H}+162+80]^{-}$, and $\mathrm{m} / \mathrm{z}$ 405, $[\mathrm{M}+\mathrm{H}+162]^{-}$, can be assigned to a glycosylsulfonate conjugate (M10 in Ref. 14). Meanwhile, $\mathrm{m} / z, 279$ and 363 could not be identified in the literature. These results suggest that this chromatographic peak at 1.68 min was produced from a mixture of diglucuronide and glycosylsulfonate conjugates and possibly other metabolites.

Interestingly, $\beta$-lapachone conjugates produce a $[\beta$-lapachone+ $\mathrm{H}]^{+}$ion in the positive-ion mode, which interferes with the analysis of $\beta$-lapachone. In the case of $\beta$-lapachone, the insource conversion of the conjugates is possible because $\beta$-lapachone has two ketone groups that are simultaneously hydrogenated before forming a conjugate. Thus, after the loss of a conjugate group in an ESI interface, a remaining hydroxyl group in a very unstable intermediate is quickly converted to a ketone group to form a stable $\beta$-lapachone ion at $m / z, 243$. Evidence of such an in-source conversion can be obtained from analysis of the chromatographic peak shape. ${ }^{22}$ If an analyte is unstable and decomposes during the HPLC separation process, its chromatographic peak would exhibit a distortion such as tailing or broadening. The peak at $1.88 \mathrm{~min}$ did not show any distortion, as shown in Fig. 1c, indicating that decomposition of the conjugates mostly occurred during the electrospray ionization process rather than during the HPLC separation process.

\section{Method validation}

After separating $\beta$-lapachone from the interfering metabolites, we fully validated our analytical method. First, we evaluated the specificity of our analytical method using drug-free blank plasma samples from six individuals and plasma samples spiked with standard $\beta$-lapachone and IS. Figure 3 shows typical MRM chromatograms of (a) blank plasma (upper panel) and blank plasma spiked with $\beta$-lapachone at the LLOQ $(0.5 \mathrm{ng} / \mathrm{mL}$; lower panel) for the transition $\mathrm{m} / \mathrm{z} 243 \rightarrow 187$, and (b) blank plasma (upper panel) and blank plasma spiked with IS (5 ng/ $\mathrm{mL}$; lower panel) for the transition $\mathrm{m} / z, 249 \rightarrow 159$

We did not observe any interfering or background substance near the retention times of $\beta$-lapachone and IS. The retention times of $\beta$-lapachone and IS were 3.20 and 3.17 min, respectively, which enabled us to rapidly determine the $\beta$-lapachone levels within $4 \mathrm{~min}$. The calibration curves for $\beta$-lapachone were linear over the range $0.5-200 \mathrm{ng} / \mathrm{mL}$, with correlation coefficients $(r)$ greater than 0.999 . The LLOQ of $\beta$-lapachone was $0.5 \mathrm{ng} / \mathrm{mL}$. The limit of detection was $0.2 \mathrm{ng} / \mathrm{mL}$. This high sensitivity enabled us to measure $\beta$-lapachone levels in human plasma at all of the time points of interest.

Table 1 shows the results of the intra- and interday accuracy and precision experiments for four different $\mathrm{QC}$ samples. The
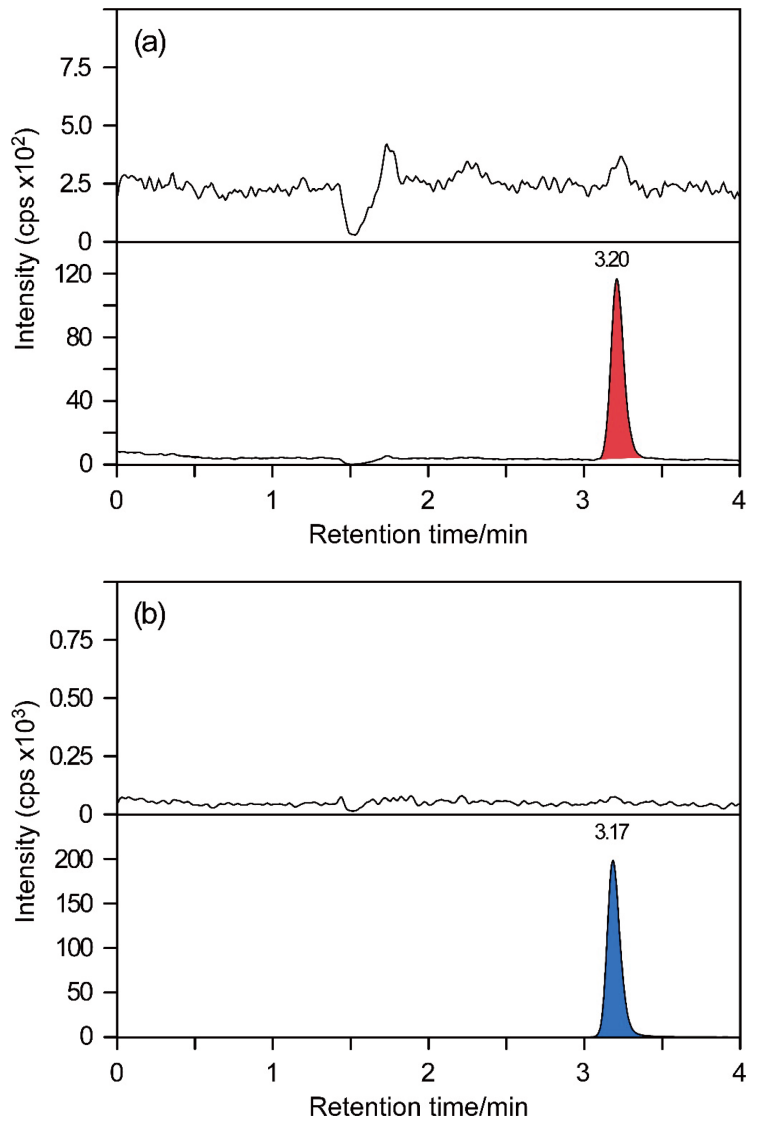

Fig. 3 Typical MRM chromatograms of (a) blank plasma (upper panel) and blank plasma spiked with $\beta$-lapachone at the LLOQ $(0.5 \mathrm{ng} /$ $\mathrm{mL}$; lower panel) and (b) blank plasma (upper panel) and blank plasma spiked with IS $(5 \mathrm{ng} / \mathrm{mL}$; lower panel). $\beta$-Lapachone and IS were monitored in positive-ion mode using the transitions (a) $\mathrm{m} / \mathrm{z}, 243 \rightarrow$ 187 and (b) $m / z, 249 \rightarrow 159$, respectively.

intraday accuracies ranged from 98.8 to $106 \%$, and the interday accuracies ranged from 96.2 to $104 \%$. The RSDs were less than $10 \%$ in both cases. Meanwhile, the intraday precisions ranged from 2.1 to $3.6 \%$, and the interday precisions ranged from 3.6 to $4.4 \%$. All of these values are within the acceptance criteria of the US FDA and the Korean MFDS, which is $\pm 20 \%$ for the LLOQ concentration level and $\pm 15 \%$ for higher concentration levels. ${ }^{18,19}$

The mean percent recovery values for three QC levels of 1.5, 16 , and $160 \mathrm{ng} / \mathrm{mL}(n=3)$ were $94.7,103$, and $103 \%$, respectively. The RSD $(\%)$ of the mean percent recovery at each 
Table 1 Intra- and interday accuracy and precision tests for QC samples at four concentration levels $(n=5)$

\begin{tabular}{|c|c|c|c|c|c|c|}
\hline \multirow{2}{*}{$\begin{array}{l}\text { Nominal } \\
\text { concentration/ } \\
\text { ng mL } \mathrm{mL}^{-1}\end{array}$} & \multicolumn{2}{|c|}{$\begin{array}{l}\text { Measured concentration/ } \\
\text { ng mL } \mathrm{mL}^{-1}(\text { mean } \pm \mathrm{SD})\end{array}$} & \multicolumn{2}{|c|}{ Accuracy, $\%$} & \multicolumn{2}{|c|}{ Precision (RSD, \%) } \\
\hline & Intraday & Interday & Intraday & Interday & Intraday & Interday \\
\hline 0.5 & $0.5 \pm 0.0$ & $0.5 \pm 0.0$ & 98.8 & 96.2 & 3.4 & 4.0 \\
\hline 1.5 & $1.6 \pm 0.1$ & $1.5 \pm 0.1$ & 106.0 & 100.8 & 3.0 & 4.4 \\
\hline 16 & $17.0 \pm 0.4$ & $16.7 \pm 0.6$ & 104.7 & 104.3 & 2.1 & 3.6 \\
\hline 160 & $168.3 \pm 6.1$ & $160.0 \pm 5.7$ & 105.2 & 100.0 & 3.6 & 3.6 \\
\hline
\end{tabular}

Table 2 Stability tests of $\beta$-lapachone in plasma under four different scenarios $(n=3)$

\begin{tabular}{|c|c|c|c|c|}
\hline \multirow{2}{*}{$\begin{array}{l}\text { Nominal concentration/ } \\
\text { ng mL } \mathrm{mL}^{-1}\end{array}$} & \multicolumn{4}{|c|}{ Measured concentration (mean $\pm \mathrm{SD} / \mathrm{ng} \mathrm{mL}^{-1}$ ) } \\
\hline & Post preparation ${ }^{\mathrm{a}}$ & Freeze-thaw cycles $(n=3)$ & Short-term ${ }^{\mathrm{b}}$ & Long-term ${ }^{c}$ \\
\hline \multicolumn{5}{|l|}{1.5 (Low) } \\
\hline Mean $\beta$ SD & $1.5 \pm 0.1$ & $1.5 \pm 0.1$ & $1.5 \pm 0.0$ & $1.6 \pm 0.0$ \\
\hline \% Relative concentration & 99.7 & 102.7 & 97.1 & 103.6 \\
\hline \multicolumn{5}{|l|}{160 (High) } \\
\hline Mean $\beta$ SD & $157.0 \pm 3.8$ & $158.6 \pm 1.4$ & $154.5 \pm 4.0$ & $145.2 \pm 0.3$ \\
\hline \% Relative concentration & 98.1 & 99.1 & 96.6 & 90.7 \\
\hline \multicolumn{5}{|l|}{100 ( $\beta$-Lapachone stock) } \\
\hline$\%$ Relative concentration ${ }^{\mathrm{d}}$ & 101.8 & & & \\
\hline \multicolumn{5}{|l|}{50 (IS stock) } \\
\hline$\%$ Relative concentration ${ }^{\mathrm{d}}$ & 102.7 & & & \\
\hline
\end{tabular}

a. After $25 \mathrm{~h}$ at $10^{\circ} \mathrm{C}$. b. After $6 \mathrm{~h}$ at $4^{\circ} \mathrm{C}$. c. After 235 days at $-70^{\circ} \mathrm{C}$. d. 37 days at $4^{\circ} \mathrm{C}$.

level was less than $3 \%$. These results demonstrate that our sample preparation procedure was consistent, precise, and reproducible.

Table 2 summarizes the results of stability tests of $\beta$-lapachone in human plasma under four different scenarios. All of the samples at low and high QC levels were stable under the tested conditions. Stored $\beta$-lapachone and IS stock solutions were also stable for up to 37 days at $4{ }^{\circ} \mathrm{C}$. All of these results ensure that our analytical method was valid throughout sample preparation, analysis, and storage periods.

\section{Pharmacokinetic study}

The validated LC-MS/MS method was applied to a pharmacokinetic study of $\beta$-lapachone in humans. Figure 4 shows the plasma concentration versus time curve of $\beta$-lapachone after oral administration of a single dose of $100 \mathrm{mg}$ MB12066 to eight healthy volunteers. Because of the poor bioavailability of $\beta$-lapachone, its levels in plasma were quite low. ${ }^{24}$ These levels, however, were higher than the LLOQ and were quantifiable at all of the time points of interest. The open circle in Fig. 4 represents the mean plasma concentration, and the red-shaded area represents the standard deviation from the mean value. Even though our LC-MS method was reliable and robust, $\beta$-lapachone levels in plasma varied greatly at most of the time points. To clearly show the large inter-individual variability in $\beta$-lapachone pharmacokinetics, we included plasma concentration profiles of four different individuals (dashed line). The cause of this large inter-individual variability is not yet well understood, and we are performing further experiments to elucidate it. The analysis of the plasma concentration profiles gave the following pharmacokinetic parameters: $\mathrm{AUC}_{\text {last }}=16.2 \pm 4.9 \mathrm{ng} \cdot \mathrm{h} / \mathrm{mL}, C_{\max }$ $=3.6 \pm 1.6 \mathrm{ng} / \mathrm{mL}, T_{\max }=3.4 \pm 1.0 \mathrm{~h}$, and $t_{1 / 2}=5.9 \pm 3.4 \mathrm{~h}$.

The LC conditions were first optimized to develop an analytical method with a total run time of $3 \mathrm{~min}$ for sufficient throughput. To achieve sub-ng/mL sensitivity, we selected the transition $\mathrm{m} / \mathrm{z}, 243 \rightarrow 187$ on the basis of the product ion

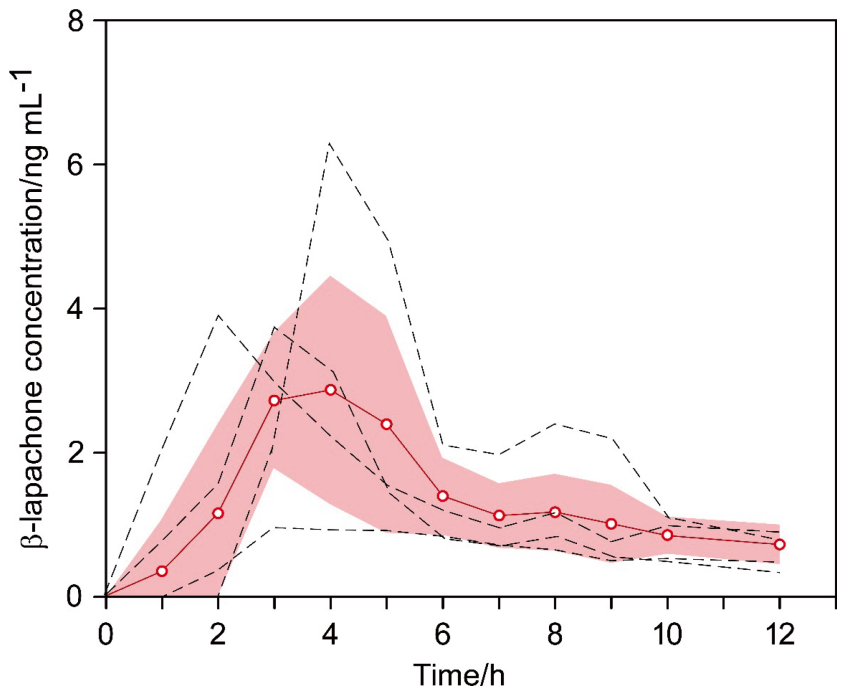

Fig. 4 Plasma concentration versus time curves for $\beta$-lapachone after oral administration of a single dose of $100 \mathrm{mg} \mathrm{MB12066}$ to eight healthy volunteers. The open circles represent the mean plasma concentration, whereas the red-shaded area represents the standard deviation from the mean value. Plasma concentration profiles of four different individuals are also included for comparison (dashed line).

spectrum of $[\mathrm{M}+\mathrm{H}]^{+}$(Fig. 1a). Blank plasma samples spiked with $\beta$-lapachone standard showed good sensitivity and specificity without any noticeable interference when they were analyzed using a mobile phase of $80 \%$ acetonitrile (data not shown). However, all clinical plasma samples obtained $3 \mathrm{~h}$ after the administration of MB12066 showed substantial interference under the same condition (Fig. 1b). To develop an analytical method with a total run time of $3 \mathrm{~h}$, we attempted to avoid the 
interference by using different transition channels such as $\mathrm{m} / \mathrm{z}$ $243 \rightarrow 159$ and $187 \rightarrow 159$; however, this approach was unsuccessful. Unexpectedly, the product ion spectra of $\mathrm{m} / \mathrm{z} 243$ for interfering peaks $(1.64,2.03$, and $2.53 \mathrm{~min})$ showed the same fragmentation pattern of protonated $\beta$-lapachone as in Fig. 1a. Given the high purity of the $\beta$-lapachone standard $(>99 \%)$, the presence of structural isomers in the drug could be ruled out. Because all blood samples at $3 \mathrm{~h}$ were collected from healthy, fasting volunteers, we reasonably assumed that the interference did not arise from food.

To separate the interfering substances from $\beta$-lapachone, we adjusted the eluent strength of the mobile phase. Fortunately, their separation was achieved when the acetonitrile content in the mobile phase was lowered from 80 to $70 \%$ (Fig. 1c). The retention time of the $\beta$-lapachone increased from 2.61 to $3.18 \mathrm{~min}$ because of its hydrophobic nature. Notably, however, the retention time associated with the major interfering peak decreased from 2.53 to $1.88 \mathrm{~min}$, whereas those associated with the two other interfering peaks at 1.64 and $2.03 \mathrm{~min}$ did not noticeably change. These results indicate that the chemical structure associated with the major peak is very different from those associated with the other two peaks.

\section{Conclusions}

This study shows that the interference of conjugate metabolites should be considered in advance to analyze human clinical samples containing both $\beta$-lapachone and its conjugate metabolites. To support this suggestion, we fully utilized the functionality of a triple-quadrupole mass spectrometer, including the precursor ion scan mode, to characterize these interfering substances. We also explained how these metabolites could be observed in the selected reaction monitoring mode. The validated analytical method could successfully determine $\beta$-lapachone levels in human plasma obtained at various time points after its administration. Our results will provide a basis for further investigating the kinetics of the conjugate metabolites of $\beta$-lapachone in our ongoing study. In addition, they will help establish strategies for LC-MS method development for the analysis of drugs in clinical samples that may contain large amounts of interference-causing drug metabolites.

\section{Acknowledgements}

This research was supported by the Brain Pool program funded by the Ministry of Science and ICT through the National Research Foundation of Korea (NRF-2019H1D3A2A02102291) and by a grant of the Korea Health Technology R\&D Project through the Korea Health Industry Development Institute (KHIDI), funded by the Ministry of Health \& Welfare, Republic of Korea (HI15C0001, HI14C2750).

\section{Conflicts of Interest}

The authors declare no conflicts of interest.

\section{References}

1. S. M. Planchon, S. Wuerzberger, B. Frydman, D. T. Witiak,
P. Hutson, D. R. Church, G. Wilding, and D. A. Boothman, Cancer Res., 1995, 55, 3706.

2. M. S. Bentle, K. E. Reinicke, Y. Dong, E. A. Bey, and D. A. Boothman, Cancer Res., 2007, 67, 6936.

3. H.-N. Kung, M.-J. Yang, C.-F. Chang, Y.-P. Chau, and K.-S. Lu, Am. J. Physiol. Cell Physiol., 2008, 295, C931.

4. S. M. Wuerzberger, J. J. Pink, S. M. Planchon, K. L. Byers, W. G. Bornmann, and D. A. Boothman, Cancer Res., 1998, $58,1876$.

5. M. M. Sitônio, C. H. de Carvalho Júnior, I. d. A. Campos, J. B. N. F. Silva, M. d. C. A. de Lima, A. J. Góes, M. B. S. Maia, P. J. R. Neto, and T. G. Silva, Inflamm. Res., 2013, 62, 107.

6. C. S. Medeiros, N. T. Pontes-Filho, C. A. Camara, J. V. Lima-Filho, P. C. Oliveira, S. A. Lemos, A. F. G. Leal, J. O. C. Brandão, and R. P. Neves, Braz. J. Med. Biol. Res., 2010, 43, 345.

7. Y.-P. Chau, S.-G. Shiah, M.-J. Don, and M.-L. Kuo, Free Radic. Biol. Med., 1998, 24, 660.

8. J. H. Hwang, D. W. Kim, E. J. Jo, Y. K. Kim, Y. S. Jo, J. H. Park, S. K. Yoo, M. K. Park, T. H. Kwak, and Y. L. Kho, Diabetes, 2009, 58, 965.

9. S. Kim, S. Lee, J.-Y. Cho, S. H. Yoon, I.-J. Jang, and K.-S Yu, Drug Des. Devel. Ther., 2017, 11, 3187.

10. H. W. Lee, S. J. Seong, B. Ohk, W. Y. Kang, M.-R. Gwon, B. K. Kim, H.-J. Kim, and Y.-R. Yoon, Drug Des. Devel. Ther, 2017, 11, 2719.

11. V. Glen, P. Hutson, N. Kehrli, D. Boothman, and G. Wilding, J. Chromatogr. B, 1997, 692, 181.

12. R. E. Savage, T. Hall, K. Bresciano, J. Bailey, M. Starace, and T. C. Chan, J. Chromatogr. B, 2008, 872, 148

13. X.-S. Miao, P. Song, R. E. Savage, C. Zhong, R.-Y. Yang, D. Kizer, H. Wu, E. Volckova, M. A. Ashwell, and J. G. Supko, Drug Metab. Dispos., 2008, 36, 641.

14. X. S. Miao, C. Zhong, Y. Wang, R. E. Savage, R. Y. Yang, D. Kizer, E. Volckova, M. A. Ashwell, and T. C. Chan, Rapid Commun. Mass Spectrom., 2009, 23, 12.

15. S. Lee, I. S. Kim, T. H. Kwak, and H. H. Yoo, J. Pharm. Biomed. Anal., 2013, 83, 286.

16. K. H. Kim, S.-H. Park, P. Adhikary, J. H. Cho, N.-G. Kang, and S. H. Jeong, Chem. Pharm. Bull., 2016, 64, 381.

17. W. C. Putnam, R. R. Kallem, I. Subramaniyan, M. S. Beg, and V. Edpuganti, J. Pharm. Biomed. Anal., 2020, 188, 113466.

18. Bioanalytical Method Validation Guidance for Industry, The US Food and Drug Administration, Silver Spring, MD, https://www.fda.gov/media/70858/download, accessed December 23, 2019.

19. Guideline on Bioanalytical Method Validation, Ministry of Food and Drug Safety, Republic of Korea, https://www. mfds.go.kr/eng/index.do, accessed December 23, 2019.

20. P. B. Phapale, H. W. Lee, M.-s. Lim, S. J. Seong, E.-H. Kim, J. Park, M. Lee, S.-K. Hwang, and Y.-R. Yoon, $J$. Chromatogr. B, 2010, 878, 2280.

21. J. J. Seo, J. Park, M. H. Bae, M.-s. Lim, S. J. Seong, J. Lee, S. M. Park, H. W. Lee, and Y.-R. Yoon, J. Chromatogr. B, 2013, 919, 38.

22. J. Y. Hyun, H.-J. Kim, M.-R. Gwon, H. W. Lee, S. J. Seong, and Y.-R. Yoon, Anal. Sci., 2015, 31, 1335.

23. I. Kim, H. Kim, J. Ro, K. Jo, S. Karki, P. Khadka, G. Yun, and J. Lee, Biomol. Ther. (Seoul), 2015, 23, 296.

24. M. Jemal and Y.-Q. Xia, Curr. Drug Metab., 2006, 7, 491. 